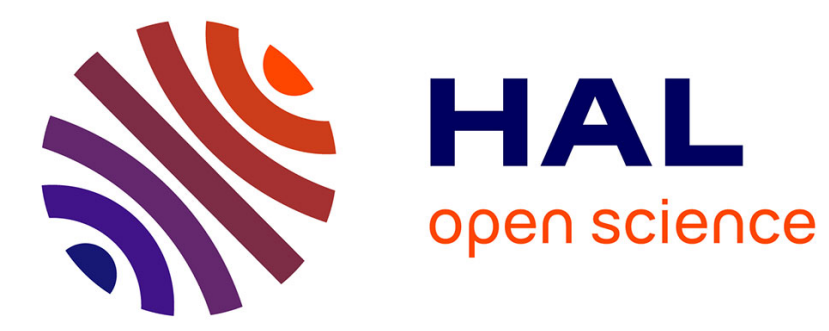

\title{
Urban Geography for the XXIth Century
}

Denise Pumain

\section{- To cite this version:}

Denise Pumain. Urban Geography for the XXIth Century. 28th International Geographical Congress , 28th International Geographical Congress, Aug 1996, La Haye, Netherlands. halshs-01707382

\section{HAL Id: halshs-01707382 \\ https://shs.hal.science/halshs-01707382}

Submitted on 12 Feb 2018

HAL is a multi-disciplinary open access archive for the deposit and dissemination of scientific research documents, whether they are published or not. The documents may come from teaching and research institutions in France or abroad, or from public or private research centers.
L'archive ouverte pluridisciplinaire HAL, est destinée au dépôt et à la diffusion de documents scientifiques de niveau recherche, publiés ou non, émanant des établissements d'enseignement et de recherche français ou étrangers, des laboratoires publics ou privés. 
28th International Geographical Congress - The Hague, august 4-8, 1996

\author{
State-of-the-Art lecture : Urban Development and Urban Life
}

by Denise Pumain, Professor, University Paris I, France

Urban Geography for the XXIth century

\begin{abstract}
:
Geographers, and especially those involved in cooperative work inside IGU for the last decades, have contributed in a significant way to provide original insights in both theoretical and practical urban issues. By developing and illustrating the concept of urban systems, they have emphasized the importance of scale effects and spatial organization in the urban realm. Comparative research at intra-and interurban scales have demonstrated the universality of the problems created by the process of urban transition, under the variety of cultural forms and socio-economic circumstances. A formalised reflexion about metropolisation trends, social polarisation, urban image and identity is already well advanced, whereas questions as the vulnerability of megacities or the elaboration of comparable indicators on an interntaional basis are still in progress. Time has also come to elaborate a new convergence between urban geography and mathematical modelling, for a better integration of spatial analysis and urban dynamics in the increasingly numerous and sophisticated urban information systems.
\end{abstract}

\title{
Introduction
}

With more than half of the world population living in towns and cities, it has become commonplace to say that we shall be living henceforward in an urban world. This means that cities do organize the world economy, that the living environment of a growing share of the world population is an urban one, and that the urban way of life dominates the collective mental representations of humanity. This general awareness, as illustrated by the organization of the second United Nations conference on Human Settlements (Habitat II or "City summit") at Istanbul in June 1996, is accompanied by significant changes in attitudes and expectations towards urban research. 
The major preoccupations of the last decades were those induced by dramatic urban growth and uncontrolled urban development. Although the gigantism of metropolises and the spatial sprawl of cities remain subjects of major concern, especially in third-world countries, the attention of specialists in the urban realm has shifted to issues of a more qualitative nature. The new key-words are mondialisation, globalisation and their related consequences such as the metropolisation trend, the new forms of vulnerability of the urban social life or the question of sustainability of large cities in their environment. They involve new inquiries in such diverse fields as the dynamics of urban systems, the formation of social links in an urban environment, the interactions between urban forms and their representations, the implication of new communication techniques in the functioning of cities and the definition of urban identities.

The emergence of such questions has prompted an exploration of new methods of investigation and planning, which would ensure a better linkage between the features and determinants of individual behaviour on the one hand, and the conception of urban spatial structures and their evolution on the other. Advances have been made in understanding the interactions between forms and processes at various geographical scales. Acknowledging the complexity of urban reality has involved a growing interest in pluridisciplinary work. At the same time, operational and fundamental researches have been helped and also urged on by the prodigious development of Geographical Information systems, which find in cities their major domain of application.

Such a context of dramatic change in all aspects of urban development and urban life requires a touch of modesty when presenting the way this new situation has been evaluated through the four-years work of a Commission of urban geographers, however deserving they may be. Fortunately this Commission has benefited from an inestimable inheritance, following in the footsteps of such renowned predecessors as Prof. W. Dziewonski and L.S. Bourne and their Commissions on National Settlement Systems (1976-84), Urban Systems in Transition (198488), and Urban Systems and Urban Development (1988-92), or the regretted Prof. J. BeaujeuGarnier who lead the Commission on World Metropolises (1980-88), as well as study groups on Urbanization in Developing Countries (1980-88) (Robic et al. 1996). The summary presented below is thoroughly indebted for their work to hundreds of geographers from many countries who have contributed closely or farther off to the work of the Commission. It is intended to be representative of the main trends in urban research and analysis of problems in contemporary urbanisation.

N.B.: in order to lighten the bibliography, references to individual contributions are made by the author's name followed by a number coding of the book of proceedings: 1 for Palomäki's volume on the Vaasa meeting (Finland, 1993), 2 for Braun's of the meeting in Berlin, 
(Germany, 1994) and 3 for the volume by R. Davies on the meeting in Cape Town (South Africa, 1995).

\section{Reconsidering paradigms: the concept of urban system}

A fundamental acquired knowledge stemming from the experience of previous commissions and more broadly from urban geographers' work is the relevance of the concept of urban system. By focusing attention on interdependences between towns and cities and on the coherence in their evolution, together emerging from and causing comparative research, this concept has widely demonstrated its theoretical value and heuristic potential.

In a world where urban changes are no longer considered mainly as a matter of quantity contriving to face the management of urban growth, but as a challenge for improving the quality of urban life, geographers have to reconsider the definition of "urbanity". One may wonder, as did L.S. Bourne (1), if the concept of urban system is still useful in this new context and if it still has a paradigmatic value for urban research. We are tempted to give a collective positive answer to such a question, provided that the concept of system is taken, not in an organisational or mechanical sense, but with its probabilistic and even evolutive connotations. It is more and more linked to the notion of urban complexity.

\subsection{Space and time scales}

This concept is not entirely new. The city as it has been built as a scientific object of study by geographers is conceived at its various levels of spatial organisation : the three levels of the individual actors, the city itself, and the system of cities, are always to be considered at least, whereas some intermediary levels such as the neighbourhoods inside cities or some regional subset of cities may also sometimes be of interest. A growing consciousness of the interdependences between those scales of analysis in urban evolutions has emerged among urban geographers. It means that an integration of the different spatial scales has to be made for a better understanding of the complexity of urban phenomena.

Another source of complexity makes the description and modelling of urban systems difficult : this is the multiplicity of time scales which are operating at the same time in the same city. For instance, one only has to consider how the timing of daily life adjusts (for instance by commuting) to the more stable pattern created by the location of jobs and housing facilities in the city. The life-time of the buildings is generally longer than the duration of stay of their users or inhabitants, or even of one generation of people. This leads to the well-known pattern of 
moves from central locations to the periphery and back to the centre, which are linked with the successive stages of the life cycle of individuals. But other time-scales, which may have a decisive and sometimes catastrophic effect on the life of its inhabitants, intervene in the life of a city: the duration of a cycle of economic specialisation (adoption of a large set of innovations) may be from a few decades to one century or more, inducing alternate periods of rapid growth, stability and slow decay. Even if cities succeed in adapting to several successive innovation waves, the speed of change of the economic and social functions is generally quicker than the speed of transformation in the town plan and infrastructure. All these differences in the time scales of the components of an urban entity cause severe dysfunctioning in the everyday life of cities, and also make the description of the dynamics of the urban systems very difficult. Not only do the relevant steps of time have to be identified, but also the mechanisms articulating various temporalities have to be considered.

Without being too deterministic, or playing with ideas about finalism, we could suggest that the articulation of such different temporalities, which is part of urban complexity, is also a condition which explains the survival and the persistency of cities over very long periods of time. The same structures can respond to very different social needs and economic activities, and this adaptability and flexibility ensures the sustainability of the whole urban system. Momentary disadaptation of form to function, congestion phenomena, time lags in adjustments to change, mismatch in facilities and infrastructure, discrepancies between real needs and the objectives of policies may result from the inequalities in the intrinsic duration of the life-cycle of each of the components in an urban system. The analytical handling of such a large variety of time-scales is very difficult and is one main source of the problems faced by urban theory and modelling when they try to conceptualise the urban change.

\subsection{Adaptive and innovative systems}

Urban systems are also complex because they cannot be wrapped up in a stable taxonomic description. The social and economic content of cities and its significance is changing over space and time. Different "generations" of towns and cities have to be characterized differently, according to their morphological aspect as well as their urban functions. These changes lead sometimes to the disappearance of some cities, to the creation of new towns or of new places for urban communities, but in most cases the transformations and adaptations occur within permanent urban entities. Indeed cities are very often considered as the main vectors of social transformation and technological innovation. This adaptation process induces more or less pronounced specializations of towns and cities and neighbourhoods into functional types. Several successive successful adaptations or failures to transform determine strong inequalities in city size. Meanwhile, the significance of size thresholds is also evolving over time. The 
qualitative content referred to by concepts such as a 'small' town, a 'large' city, a 'metropolis' of international level, an 'industrial' or an 'administrative' one, has to be constantly revised.

As it concerns innovation and creation, this particular process of urban change is very difficult to include in models which attempt to make predictions. Even when general trends in evolution have been identified as internationalisation of the economy, opening of urban markets, dedensification of urban centres, extension of suburbanisation...there is no instantaneous, nor mechanical nor universal "response" to be expected from the urban systems submitted to those trends. According to local conditions, to the timing of their previous evolution, urban systems may react in quite different ways. This makes the identification of actual general "trends" difficult, controversial, and perhaps problematic. Indeed, diversity, creation of new products and ways of doing things have always been a characteristic of the urban phenomena. There are no predetermined alternatives for urban evolution which would form the guidelines for the trajectories of cities. Actually, cities are permanently inventing their own evolution.

The innovation process itself is also a source of complexity in the sense that the integration of social interactions in a temporal accumulation produces networks of relations which have a long existence and persist well beyond the migrations of people and even the passage of generations (Dematteis, 2). The analysis of institutions and the political economy of conventions lead to such conclusions. Towns and cities become indivisible objects and cannot be analysed as the juxtaposition of their different parts. It is highly significant for instance that a conurbation resulting from the merging of two or three independently grown cities will not reach the same functional level as a unique monocentric city of the same size before a very long time (many decades or centuries).

\subsection{Local interpretations of global trends}

One more difficulty for understanding urban complexity is the fact that the same mechanisms, or rules, or planning principles, may lead to different structures, according to the situation of the city under study and the moment of its evolution. The same action (external perturbation or internal change) may have no effect if the city is on a stable dynamic trajectory, but it can deeply alter the structure if it intervenes at a moment of instability, when bifurcations are possible (Pumain, 2).

Pieces of knowledge about the complex behaviour of urban systems emerge from our comparative work. This explains that no simple answer can be brought to most alternative questions which oversimplify the problematics of the future urban evolution, as quoted again by L.S. Bourne : Which dominant trend should appear as a consequence of the growing 
internationalisation of economies and societies and of the contemporary main technological and political changes? :

- will urban systems react by drastic modifications of their spatial organisation, or will they adapt their structure within the general pattern of stability which characterized their evolution, even during the dramatic changes linked to the urban transition of the last century ?

- are urban structures evolving towards more concentrated or decentralised patterns, at the different scales of observation?

- is there any convergence of urban profiles toward a growing economic and/or social and cultural homogeneity, or is social and economic heterogeneity increasing?

No straightforward answer can be given to any of those questions without considering precisely at which kind of place and at which spatial and temporal scales of analysis the phenomena occur. The consequence is a necessary restructuring of the field of urban research, intertwining previously separated themes and scales of analysis. It was a suggestion of that Commission to prepare "intelligent" monographs on cities enlarging the traditional way of considering an urban case, mainly through site, situation, plan, functions, and so on, by developing new concepts which tend to integrate the idea of complexity and the simultaneous consideration of several scales of analysis.

Whatever the spatial scale of analysis, in the case of cities as well as in the case of whole national settlement systems, we also emphasize the necessity of considering evolutions over periods long enough for them to be interpreted correctly. Urban systems are continuously adjusting their structures, causing many temporary fluctuations in the trajectory of the main state variables which are currently used for their description. Moreover, many trends present temporal curves which have a cyclical aspect, for instance because of the changing relation to city size over time induced by the hierarchical diffusion of innovation and urban changes. Errors have been made by interpreting too hastily momentary inflexions as dramatic "reversals" in the general evolution.

A major consequence of this change of paradigm is the relative loss of confidence of the decision-makers. When conceiving the future of one city, trends can no longer be seen as the prolongation of the past. Local strategies also cannot limit themselves to choices inspired by the general context of urbanisation trends, since even the best recipes when applied to different situations may not work at all. A progressive consciousness of the advantage of substituting anticipation for imitation is emerging in urban marketing and strategies of development.

Some examples illustrating the complexity of contemporary urban evolutions have been selected below, without pretending to reflect fairly the entire work of our Commission. 


\section{Urban Development : Changing perspectives on urban actors}

Since World-war Two, a number of structural transformations have affected the social organisation of the economy, the nature of production and the geographical scale of interdependences between places. How such a context is changing the content of urban activities and the significance of urban development is one of the major questions faced by urban geographers. It also incites them to emphasize the role of new actors and practices in the urban environment.

\subsection{The restructuring of urban economies}

Whatever the admitted concept describing our post-industrial, information or knowledge-based society, the service sector is perceived as becoming more and more the main economic base of cities. The general methodology inspired by central place theory is still effective by helping to distinguish between banal widely-diffused services activities which develop proportionally to the resident population, and specialised services creating specific specialisations and inequalities in development among cities in the urban competition. Examples are given for the Toronto region (Preston, 2, Simmons, 2). The development of business services and especially financial centres is put forward as a significant indicator of a growing urban economy. International activities such as tourism are also analysed in that perspective, for instance in the case of Tallin (Kuus, 2). Cities of developing countries do not escape the process, as illustrated by changes in the CBD of Harare (Cumming et al., 3). However, it would be an oversimplification to conclude that old industrial centres are definitively fixed in economic and social decay, as demonstrated by studies of Detroit (Sinclair, 2) or by studies about smaller cities of former East Germany (Cassel, Schwaderer, 2).

\subsection{The informal sector}

A fast growing set of tertiary activities in cities of developing countries belong to the so-called informal sector, as described for instance for Mexico (Aguilar, 2), or China (Dao Qi, 2). The attitude towards urban informal activities has changed. Lately, they used to be conceived as a more or less parasitic form of economy, impeding a real development and contributing to maintain people in poverty. Detailed field studies have reversed this too limited view and revealed the specific role of the informal sector in the learning processes of newly immigrated populations in the urban milieu. It may also represent a non-negligible source of income. Once more, results from local studies provide contradictory results : in some cities such as 
Hyderabad, India, informal activities appear as an instrument of new gender division of labour and a source for a possible change in status for women (Reddy and Rajkumar, 2), whereas around Lake Chad in Cameroon informal trade is mainly a practice of foreign refugees and seems to weaken the national economy (Simeu-Camden, 2). In both cases however the informal sector provides several fundamental forms of elementary social links which are the basis for the integration of new populations into the urban environment.

\subsection{Urban image and marketing}

It may be a consequence of the growing influence of communication and the media in our societies that urban images and awareness about their importance are progressively incorporated into the general know-how of urban decision-makers (Borchert, 2). The use of images for competitive purposes by cities and attempts to modify the way they are perceived are by no means a recent phenomenon. However, it is only during the last ten or fifteen years that cities have multiplied their marketing efforts. This concern can be explained, firstly by the development of our information society which exacerbates competition between cities, secondly by the above-mentioned trend toward growing importance of services in the economic bases of cities, inducing the urban authorities to develop market-oriented strategies for attracting those foot-loose activities (Dematteis, 2).

Urban marketing studies have been classified in various types corresponding to unequally professional strategies and objectives: from place promotion and urban advertisement to new image definition. Various instruments are used for promotion, from historical heritage and architecture to public art and festivals (Borchert, 2 and 3). Less frequent is a reflexion about the complexity of the process of urban identification and definition of an identity. This would substitute for the static idea of an urban patrimony a more dynamic concept of an urban milieu, made up of competing, co-operating and conflicting groups. The marketing policy could "connect the sense of belonging with mobilisation aimed at change, and the subjective identities of the individual components with the collective identity of the city as self-organised system" (Dematteis, 2, p.436). Such images have been experimented within promoting cities like Glasgow, Toulouse, Annecy or Antwerp. Other examples are given in the specific case of double cities (Buursink, 2 and 3). New policies for "smart development" may in the long term replace competition for growth. In many cases, the use of urban images is however limited to very standardised operations of promotion.

Other studies however emphasize the role of private-public partnership for inserting urban marketing into planning strategies, for instance in the German experience (Helbrecht, 2) as well as the specific role of "mega events" such as the application to become the European Cultural 
City of the Year by Bergen (Sjoholt,2), Helsinki (Haarni, 3) or Copenhagen -actually elected for 1996 (Andersen and Matthiessen, 2), or the competing bids for the organisation of the Olympic games of 2004 by Durban and Cape Town in South Africa (Davies, 2). Those last studies also emphasize two conditions for efficiency in city marketing : the generic definition of urban qualities and their identification and description in terms appropriate to the target group it wishes to impress.

If operational methods for urban marketing are improving over time, urban identity as a "hidden face of the city" (Racine, 2) has still to be explored in the theoretical framework of urban geography. Several epistemological ways are suggested of defining what makes urban identities, answering such questions as "do cities have a soul?", building a "mental ecology" or finding the secret of urbanity and its follower "metropolity" (Racine, 2). The question of complexity arises again when considering the process of how an urban collective identity may emerge from individual symbolic values and aspirations to social distinction, through the interactions between the level of individual representations and the more aggregated level of urban images.

\section{Urban Life: The city as a territorial and social entity}

Under the controversial denomination of "post-modernism", several authors have analysed the social and intellectual counterpart ot those contemporary evolutions, as well as their geographical consequences. Contradictory tendencies are hypothesized : on the one hand the widening of relationships between all parts of the world leads to a diffusion of various cultural features which may be used and "quoted" far away from their place of origin; the consequences in the urban realm would be a trend towards more diversity inside each city (multiculturalism in society, pluralism of cultures, eclecticism in architecture, relativism in intellectual interpretations) and more uniformity between cities. On the other hand, the globalisation of the world economy and the ideological domination of liberalism would lead to reactions reaffirming local identities and particularisms, exacerbating for instance ethnic tensions and social polarisation inside cities.

\subsection{Toward an increasing social polarisation inside cities?}

Detailed field studies throw a doubt on the often accepted idea according to which an increasing social polarisation should be the necessary price to pay for participation in a high level of connexity to the main nodes of the world economy. Here again, there is an oversimplification induced by the abusive generalisation of such theories as the globalisation 
theory, linking the central position in world networks to social and spatial segregation and the increasing difficulty of social integration.

The shape and evolutionary trend of the spatial organisation of social groups of income inside cities appears to be not so much a consequence of an abstract "law" of the real estate market as of social, political and cultural choices. For instance, the decay of housing and the concentration of the most deprived groups in inner cities is not a universal fate. In some countries, a clear and conscious choice has been made in favour of valuating the city center, for instance in Warsaw (Korcelli et al., 2) as in most European countries. However in the European continent an increasing spatial segregation is occuring in several places, for instance in Turin where it accompanies the de-industrialisation process (Petsimeris, 1). Elsewhere, there are still hesitations in the trend towards gentrification of inner cities, as illustrated in the case of the central neighbourhoods of a few Canadian cities, which may be related to the aspirations of one particular generation of people (Ley, 2). Indeed, patterns and processes of change are more complex than is generally assumed, as suggested by a study of income inequalities in Canadian cities (Bourne, 3), as well as the spatial pattern of ethnical groups in greater London when disaggregated by levels of social status (Petsimeris, 3 ).

The most striking examples of contradictory urban evolution may be found between North America and South Africa. The formation of new urban ethnically homogeneous communities in some North-American suburban areas, and its extreme forms of "gated" or "walled" communities has been analysed as a specific cultural and political process. By its extreme and "pure" character as a social and spatial form, this may appear as a model but can by no means be interpreted as a general trend for the evolution of urban socio-spatial structures all over the world. Even in North America, most communities have only a partial and flexible character; they are oriented to specific aims and do not englobe all aspects of local social life (Davies W.K., 1). The end of apartheid in South Africa has led to a tremendous social change and to an immense spatial reorganisation of the administrative structure of the territory. Municipalities have been redelimitated in order to associate urban white communities and parts of the former black townships or "coloured" neighbourhoods (Davies R.J., 1). The specialised workshop on social segregation, integration and urban transformation held during the Cape town meeting includes some twenty contributions with detailed studies of contemporary changes occuring in various South African towns and cities, examining the desegregation process through questions like urban governance (Maharaj, 3, Simon, 3), policy (Parnel, 3, Simon, 3) and planning (Lemon, 3), economic activities and development (MacCarthy, 3, Rogerson, 3, Grant et al., 3), home ownership and social status (Donaldson, 3, Fairhurst et al., 3), population and household dynamics (Spiegel et al., 3, Rule, 3, Myburg, 3, Geyer, 3), relationships between ethnic communities and economic groups (Fox, 3, van der Merwe, 3). 
From detailed studies of the contemporary evolution of intra-urban social and spatial structures, it would be difficult to conclude to a simple general trend towards an increased heterogeneity or homogeneity in the repartition of social, ethnic or income groups in the urban space. First, according to the cultural and political history of each country, the thresholds of the intensity of social and spatial segregation which determine an action in favour of regulation are very different. For instance, American ghettos may be monocultural at $60 \%$ and more, whereas in Europe a concentration of $20 \%$ of one type of population in a neighbourhood is already identified as a serious problem. Second, national and local policies about interventions on the housing market and in urban planning have a decisive impact on the spatial organisation of income groups inside cities.

Observations of postmodernism trends in urbanism and multiculturalism in urban social practices can be made in various parts of the world, as in Hout Bay at Durban (Olofse, 3). But new schemes of explanation are not always connected to significant changes in reality: for instance, an evaluation of differences in quality of life in Chinese cities still reveals a strong correlation with the income level of the population (Jingke, 1). Consistent planning of new towns may be a way of improving greatly the quality of suburban life, as demonstrated for example in Tama city, close to Tokyo, by Tanuichi (1). Several studies show that what is now called "social exclusion" remains actually mainly a matter of pauperisation. The effects of poverty are worsened by the severing of social ties, marginalisation of social or ethnic groups and denial of social rights, and are also probably reinforced by some design of urban spatial structures. Still, the main question is a matter of social and spatial distribution of income and power. Actually, the application of "post-modernism" to urban geography still remains problematic, and should not necessarily lead to the adoption of relativism in science as shown by W.K.Davies, (3). The conclusion of this last enquiry goes in the same direction as what already appears as the leitmotiv of this paper : "the result (of new tendencies) is even more complexity in city structures".

Complexity can be tractable when several points of view and scales are considered simultaneously. For instance, it is as a result of several studies that the changes in suburbanization trends, which may puzzle a superficial observation, can be largely understood, and perhaps predicted, if the compositions of urban population in groups of different age and mobility behaviour are carefully considered (Illeris, 2, ). Analysis of planning issues shows clearly the linkages between chosen orientations and the scale of operation and power of leading groups of interest (for instance about central Helsinki, (Haami, 2) or Turku (Andersson, 2)). 


\subsection{Urban vulnerability and sustainability}

Perhaps referring to knowledge of living systems may help us to conceive that the contemporary urban evolution leads towards an increasing power of urban control of human activities and at the same time to an increasing vulnerability of urban systems. When the system becomes too specialised, if there are not enough redundancies in the multiple links which ensure its complexity, if its dependance regarding a single resource or a type of environment for instance becomes too narrow, the growth of the system may increase its vulnerability. But an increase in complexity also means a growing diversity in the urban system, which increases its stability and develops its creativity and ability to respond to an enlarged variety of external perturbations.

About the theme of urban vulnerability : according to our experience, it is still largely a matter of internal organization, the cohesion between various social and cultural groups, the quality of "social links" and of the integration processes in urban society are much more frequent factors of unstabillity in the history of a cities than possible "external" perturbations like "natural" catastrophes. This remark is by no means intended to deny the existence of the risks associated to a bad management in the use of resources and prevision of hazard events, for which a real pluridisciplinary research still has to be developed. The idea is put forward however that human decisions, urban policies, are of tremendous importance in what is called the "sustainability" of cities, and this even when apparently "pure" environmental circumstances are considered.

\section{Revisiting the dynamics of urban systems}

The magnificent work accomplished by the preceeding Commissions on urban Geography in identifying the main general characteristics and local specificities of urban systems has been carried on by several studies trying to determine how their structure would react to the actual context of developing more international linkages. The general result is that the contemporary evolution of urban systems does follow general trends but with typical variations, according to their stage of development and depending upon their geographical situation respective to world main trade flows. Local policies may however produce a few significant inflexions.

\subsection{Precisions about the evolution of urban systems}

The importance of geographical situation in the reaction of urban systems to globalisation trends has been assessed during a special session devoted to urban systems of the "periphery", 
like those of Finland (Palomäki, 1) or Estonia (Marksoo, 1). This conclusion is also a significant result illustrated by many attempts at measuring the degree of international integration of urban systems, after various sources of possible linkages. Examples of such tentatives have been made for cities belonging to the Polish (Korcelli, 1), Japanese (Fujita, 2) and Finnish (Palomäki, 2) urban systems, for a large set of cities of the European community (Rozenblat, Pumain, 2), or for fast growing capitals such as Seoul (Kim, 2). At a lower level, inside each of those systems, a clear differentiation appears in the intensity of the internationalisation process between a few centres (usually the capitals, sometimes specialised cities) and the other cities belonging to the urban system.

The concept of urban systems in transition applies particularly well to those of Eastern Europe where integration into the international flows of market economy on the one hand and processes of denationalisation and privatization on the other have been major perturbations. A full range of detailed studies have shown that, in most countries, the predictable consequence of this opening could be an accelerated trend towards metropolisation, whereas the development of the main capitals had been successfully contained until then (Rey, 2, Pak, 2). However, the trend could be revealed as ineffective if the general level of the metropolises by international standards was not already high enough. However, the geographical situation of cities (for instance proximity to border lines) and their rapid connexion to major international transportation infrastructures could be decisive issues for the selective development of some cities, leading to significant restructuring of the existing urban hierarchies (Korcelli, 1, Rey, 2, Grimm, 2).

Regional development policies may indeed have a significant impact on the structure of urban systems, if they are conducted with full determination. Examples have been provided for Sri Lanka (Wanasinghe, 1 and 2), Argentina (Gomez-Insausti, 1), Bangladesh (Saleheen et al., 1) and Cameroon, where several "generations" of cities can be related to the dominant political group of specific periods (Simeu-Kamden, 1).

\subsection{Global networks and fragmented systems?}

The contemporary evolution of urban systems also has been submitted to the other "postmodern" hypothesis of an increased participation of urban structures in international networks, in the form of a deepening gap between a few nodes of flexible accumulation, intensively connected and participating to the main decision centers of those networks, the so-called "global cities", and the other cities, lagging behind and possibly tempted by new affirmations of their identity by returning to practices of parochialism. Parallel to this interpretative 
framework is formulated a hypothesis about the declining role of the state as a significant level for spatial organisation.

Such generalisations hardly resist careful analysis of actual evolution, for instance in the well documented European case. It is true that the opening of borders to international trade and the adoption of new technologies of communication has prompted a stage of "metropolisation", inducing more rapid transformations in the largest cities than in the smallest ones. But even if the effects of internationalisation are momentarily more concentrated in metropolises, many examples of their partial diffusion in other centers may be found. Moreover, the progressive emergence of an urban system shaped on the European scale is already noticeable. It is henceforward at that level, and no longer inside each national country, that the secular trend to the reinforcement of the hierachy in urban systems has to be considered. The uneven participation and benefit of European cities from this "innovation" can already be understood (and predicted with reasonable probabilities for the next decades) from various properties of cities, including the status of capital, a previous specialisation in urban functions, proximity to international boundaries, and relative rank in their national urban system. Such studies also confirm that the national boundaries are still effective in reducing the level of spatial interactions, and show no generalised impact of fragmentation tendencies, except in the revival of a few cultural aspects, including the exploitation of regional or local identity and patrimony for marketing and social integration purposes. Contrary to the common belief in fastsucceeding intellectual fashions, summoning up the already existing theoretical knowledge about the dynamics of urban systems may appear as an efficient method for understanding how cities are evolving in a changing international context.

\subsection{Towards a formalisation of the dynamics}

The regulation of urban systems is not entirely determined by external global trends in the evolution of economy and technology. The evolution of urban systems is perhaps not mainly a matter of any "external" conjuncture. As other self-organised systems, they have relatively autonomous rules of development. The main general features of their dynamics are partly predictable because they are very common. They are linked with the competing spatial and hierarchical structure of urban systems and with the universality of the "urban transition" processes. As a first approximation those general principles of urban systems dynamics can be used for shaping rough previsional scenarios for a few decades of future evolution. They are of great help in interpreting rightly the highly fluctuating temporal behaviour of urban growth.

The best example of this is the theory of "counterurbanization", which was correct in describing the trend of decentralisation of intra-urban population densities but wrong at the 
scale of national urban systems. This error was indicated early by a few specialists in the longterm evolution of urban systems. It has been confirmed by the observed evolution at the end of the eighties and during the nineties. Indeed, several contradictory trends have been reported and interpreted according to the situation of each urban system in space and time : for instance in Mexico during the eighties a trend of diffusion of economic development was observed in the medium-sized and small cities (Aguilar, 1); in Estonia, the A. Marksoo (1) also noticed a decentralisation trend but suggested a hypothesis of a shift to metropolisation in the near future, since the spatial evolution of resident population was in contradiction with the creation of employment in large cities; the Finnish urban system has a composite evolution, more intensive in the south and extensive in the north of the country (Palomäki, 2); at the European scale, a process of metropolisation has been identified, but correct predictions about the future evolution of cities can be made only if one considers not only their rank in the European urban hierarchy but also their function in their national territory and their geographical position respective to international boundaries (Rozenblat, 2).

The past misunderstanding about counterurbanisation trends could be replaced by another one if the actual trend to "metropolisation" or reinforcement of the urban hierarchies through a quantitative growth and/or qualitative improvement of the structures of the largest cities were to be interpreted as a definitive and linear trend. On the contrary, the actual state of knowledge about the evolutionary process of urban systems leads us to interpret this new trend merely as the first stage of an innovation cycle linked to the widening scope of inter-urban linkages permitted by the increasing speed of communications between cities. The metropolisation effect should be reduced, stopped or even reversed as the effects of that innovation will be progressively extended to the other parts of the urban systems.

Fragments of urban theory have been already included in urban models using the concepts of complex systems theory, both at intra-urban (Portugali, 2) or inter-urban scale (Pumain, 2). Urban models have been inspired by new theories as self-organisation theory, (sometimes referrred to as chaos theory), or individual random choice theory, and confronted to various new methodologies like fractal measurements or neural nets. Promising results are already obtained from computerised simulation methods such as cellular automata or multi-agent systems, which are more flexible than mathematical models of differential equations for modelling the many spatial interactions which are producing the dynamics of urban systems. Many efforts are still needed however for directing urban modelling efforts toward an improvement of our understanding of urban processes and to develop empirical research which would be guided by the acknowledgment of urban complexity. As urban geographers, we would estimate ourselves satisfied if we succeed in directing attention against excessive 
simplification and too easy interpretations, as oriented by some ideologies or mediatic complaisances.

\section{Conclusion}

As at the beginning of this conference, we invoked modesty and humility. To the big challenging questions of the time about the future of cities and urban systems, the work of our Commission does not bring clear-cut answers, nor inspired predictions, nor ready-to-use managing recipes. Our contribution could be interpreted mischievously as another version of the bashful intellectual discourse saying: "the question is badly put", or, even worse: "things are much more complicated than that". Actually we do say that the alternative questions, as they are quoted by the media, are too simple, because the future of our cities is not embedded between already fixed opposite tendencies. It is constantly inventing itself in a mix of many simultaneous acting forces. To all problems there are more than two opposite solutions.

We would like to clarify the meaning of the concept of complexity. Claiming its importance is not an incantation, but a call for more field investigation and comparative analysis. Its main usefulness is to help in recognizing significant geographical entities, which may be observed in a persistent way, at various scales in space and time, and whose behaviour cannot be reduced to mechanical reactions to external stimuli. This does not mean that their evolution is not understandable; sometimes it may even be predictable. We have the ambition to identify some of the properties which make systems react differently to the same general historical context. The stage in the development of urban systems, their geographical situation in a given region of the world, but also the peculiarities of their cultural history and the political choices which are made are among the most significant features which emerge from comparative analysis as key-factors for our understanding.

Urban systems may be viewed as an invention of humankind for reducing the uncertainties and hazards of a local environment by developing networks which increase accessibility to the resources of other places. At the moment this seems quite successful at the level of systems of cities, with a growing globalisation process. But uncertainties seem to be increasing at the level of each city, concerning the sustainability of its development, its ability to create jobs and wealth, and its vulnerability to social and technological risks. Uncertainties are also part of the everyday life of a growing number of urban citizens, experiencing precariousness of life through poverty and violence. We do hope that urban research could contribute to the reduction of those hazards, whether natural, social or technological, by developing a better integrated and comparative knowledge of urban complexity. 
Our main concern of the last four years could be summarized as an effort to make explicit the content of the small word "and" in our broad theme "Urban Development and Urban Life". After a period of deconstructing concepts, reconsidering data and exploring new ways of research, our research agenda for the future is to continue to explore the following themes: metropolisation and evolution of the role of small and medium-sized towns in urban systems; connections between trends in world economy and local urban development; social polarisation, "natural" hazards and vulnerability of cities; indicators and evaluation of urban quality of life; new local governing and urban planning methods. This also should include a better theoretical formalisation of our results, an increased effort at providing comparable indicators on an international basis and a cooperative work for adapting our means of research to the social and institutional needs of our urban planet.

\section{References}

(2) Braun G. O. (ed) 1994, Managing and Marketing of Urban Development and Urban Life. Berlin, Dietrich Reimer Verlag, Abhandlungen Anthropogeographie, 52, 687 p.

(3) Davies R. J. (ed) 1996, Contemporary City Structuring: International Geographical Insights. Cape Town, Society of South African Geographers, $541 \mathrm{p}$.

(1) Palömaki M. and Karunaratne J.A. (eds) 1995, Urban Development and Urban Life. Acta Wasaensia, 45, Geography, 6, 382 p.

Robic M.-C., Briend A.-M. and Rössler M. (eds), 1996, Géographes face au monde. L'Union Géographique Internationale et les Congrès Internationaux de Géographie. Paris, L'Harmattan, $464 \mathrm{p}$. 